\title{
ANALISIS KESEDIAAN PETANI PADI SAWAH DALAM MEMBAYAR JASA LAYANAN PENGELOLAAN IRIGASI DI DAERAH IRIGASI WAY KETIBUNG KABUPATEN LAMPUNG SELATAN
}

\author{
THE ANALYSIS OF WILLINGNESS TO PAY FROM FARMERS TO \\ MANAGEMENT IRRIGATION SERVICE OF WAY KETIBUNG'S IRRIGATION \\ AREA IN LAMPUNG SELATAN
}

\author{
Fembriarti Erry Prasmatiwi*1 ${ }^{1}$, Raden Hanung Ismono ${ }^{2}$, Tunjung Andarwangi ${ }^{3}$ \\ Program Studi Magister Agribisnis, Fakultas Pertanian, Universitas Lampung \\ J1. Soemantri Brojonegoro No 1, Bandar Lampung \\ *E-mail: fembriarti.erry@fp.unila.ac.id \\ (Diterima 08-04-2021; Disetujui 03-06-2021)
}

\begin{abstract}
ABSTRAK
Air merupakan salah satu faktor penting untuk budidaya padi sawah. Salah satu sumber pengairan padi sawah yaitu irigasi sehingga keberadaannya perlu dijaga dan dikelola dengan baik. Petani berperan penting dalam upaya pengelolaan irigasi. Kontribusi petani dapat dilaksanakan dalam bentuk kesediaan petani membayar (WTP) jasa layanan pegelolaan irigasi guna perbaikan dan pengelolaan irigasi. Manfaat dari pembayaran jasa layanan pengelolaan irigasi yaitu dapat digunakan untuk perbaikan dan pengelolaan irigasi sehingga kecukupan air tetap terjaga. Adapun tujuan dari penelitian ini yaitu untuk mengetahui nilai kesediaan membayar dari petani pemakai irigasi di Daerah Irigasi Way Ketibung Kabupaten Lampung Selatan, dan faktor-faktor yang mempengaruhinya. Penelitian dilaksanakan di Kecamatan Sidomulyo dan Candipuro, Lampung Selatan dari bulan Juni sampai September 2020. Jumlah sampel penelitian yaitu sebanyak 100 petani padi irigasi yang dipilih dengan menggunakan metode propotionate random sampling dari total populasi sebanyak 1.223 petani padi irigasi. Data dianalisis dengan menggunakan metode penilaian kontingen (CVM) dan logistik ordinal. Hasil penelitian diperoleh bahwa nilai WTP ratarata jasa layanan pengelolaan irigasi di Daerah Irigasi Way Ketibung sebesar Rp97.400,00/Tahun atau Rp48.700,00/Sesi Tanam dengan faktor-faktor yang mempengaruhinya adalah luas lahan dan pengetahuan petani tentang fungsi irigasi.
\end{abstract}

Kata kunci: WTP, Petani padi irigasi, Daerah irigasi Way Ketibung

\begin{abstract}
Water is one of important things for the process of rice field farming. Irrigation as one of water sources for rice farming needs to be managed and maintained. The role of farmers is very important for irrigation management efforts. The contribution of farmers in the repair and management of irrigation can be realized in the form of willingness to pay (WTP) of irrigation management services. The benefit of paying for irrigation management services is that it can be used for better irrigation management and maintained water adequacy. This study aims to determine the value of willingness to pay from farmers that use irigation from the Way Ketibung's Irigation Area in Lampung Selatan regency, and the factors influence it. Data collection was conducted in Sidomulyo and Candipuro district, Lampung Selatan in Juni-September 2020. The number of samples of this research is 100 farmers who used irrigation for rice farming selected by using propotionate random sampling method from total population of 1223 farmers. The data are analyzed using contingent valuation method (CVM) and ordinal logistic. Based on the research results, average WTP value of irrigation management service in the Way Ketibung's Irigation Area was IDR97,400.00/Year, or IDR48,700.00/Planting Session. The factors that influenced were land area and farmer's knowledge of irrigation function
\end{abstract}

Key words: WTP, Irrigated rice farmers, Irrigation area of Way Ketibung 


\section{PENDAHULUAN}

Kebutuhan beras masyarakat yang terus meningkat mendorong terciptanya peningkatan produksi padi. Ketersediaan air berpengaruh terhadao produksi padi dengan rata-rata kebutuhan air bagi tanaman padi adalah 1,20 lt/dtk/ha (Indah dkk, 2015). Besarnya kebutuhan air untuk tanaman padi akan mempengaruhi proses pertumbuhan tanaman dan berpengaruh terhadap produksi dan keberlanjutan usahatani padi sawah. Oleh karena itu, ketersediaan air harus tetap terjaga sehingga perlu adanya pengelolaan sumber air, tidak terkecuali bagi petani padi yang berada di wilayah irigasi Way Ketibung.

Way Ketibung merupakan salah satu irigasi di Kabupaten Lampung Selatan dengan luas 32.061 ha $\left(320,61 \mathrm{~km}^{2}\right)$ dan panjang sungai $9,11 \mathrm{~km}^{2}$. Berdasarkan Peraturan Daerah Kabupaten Lampung Selatan Nomor 15 tahun 2012 tentang Rencana Tata Ruang Wilayah Kabupaten Lampung Selatan tahun 2011-2031 menyatakan bahwa Daerah Irigasi (DI) yang merupakan kewenangan pemerintah kabupaten/kota meliputi DI Way Katibung seluas kurang lebih 1.550 hektar. Tipe irigasi di Kabupaten Lampung Selatan terdiri atas irigasi teknis dan setengah teknis (Indah, 2015). Menurut Dinas PU
Kabupaten Lampung Selatan (2014), daerah irigasi Way Ketibung secara administratif melewati beberapa kecamatan di Kabupaten Lampung Selatan antara lain Kecamatan Candipuro, Kecamatan Ketibung, Kecamatan Marbau Mataram, Kecamatan Sidomulyo, Kecamatan Tanjung Bintang, Kecamatan Tanjung Sari, dan Kecamatan Way Sulan.

Ketersediaan air di daerah irigasi Way Ketibung sangat tergantung pada pengelolaannya. Kegiatan pengelolaan membutuhkan pembiayaan dalam penerapannya di lapangan. Pembiayaan dalam upaya pengelolaan dapat dilakukan dengan penerapan pembayaran jasa layanan pengelolaan irigasi. Pembayaran jasa layanan pengelolaan irigasi merupakan instrumen berbasis pasar dengan tujuan konservasi berdasarkan prinsip yaitu siapa yang mendapatkan manfaat dari jasa layanana pengelolaan irigasi harus membayar dan siapa yang menghasilkan jasa tersebut harus dikompensasi (Sudarma dkk, 2014). Pembayaran jasa layanan pengelolaan irigasi antara penyedia dan penerima akan mendorong adanya kegiatan konservasi, salah satunya konservasi air (Dasrizal dkk, 2012). Instrumen dalam pembayaran jasa layanan pengelolaan irigasi yaitu penyedia (Provider) dan penerima (Buyer). 
Penelitian ini hanya fokus pada penerima jasa layanan pengelolaan irigasi air irigasi Way Ketibung di Kecamatan Sidomulyo dan Candipuro. Dimana besarnya kesediaan membayar jasa layanan pengelolaan irigais akan dihitung dengan menjumlahkan beberapa indikator antara lain iuran perbaikan irigasi, biaya gotong royong, iuran buka tutup pintu air, pajak lingkungan, dan iuran penanaman bunga sepanjang galengan. Menurut Dieny dkk (2018), organisasi yang dapat membantu pengelola WTP dari petani untuk disalurkan ke provider dapat berupa P3A, LSM, Pemerintah Desa, dan kelompok tani. Provider dapat berupa badan layanan usaha yang dibentuk pemerintah daerah yang diperuntukan untuk mengelola dana WTP.

Berdasarkan permasalahan tersebut maka perlu diadakan penelitian terkait kesediaan petani dalam membayar jasa layanan pengelolaan irigais di daerah irigasi Way Ketibung, sehingga penelitian ini bertujuan untuk: (1) Menganalisis nilai kesediaan petani membayar jasa layanan pengelolaan irigasidi daerah irigasi Way Ketibung Kabupaten Lampung Selatan. (2) Menganalisis faktor-faktor yang mempengaruhi petani dalam membayar jasa layanan pengelolaan irigasi di daerah irigasi Way Ketibung Kabupaten Lampung Selatan.

\section{METODE PENELITIAN}

Penelitian dilaksanakan di Kecamatan Sidomulyo dan Candipuro, Kabupaten Lampung Selatan dengan pertimbangan bahwa Kecamatan Candipuro dan Sidomulyo merupakan dua kecamatan yang sumber irigasinya berasal dari daerah irigasi Way Ketibung. Waktu penelitian dan pengumpulan data yaitu bulan Juni hingga September 2020 dengan menggunakan metode survey. Teknik pengambilan sampel yaitu dengan menggunakan teknik propotionate random sampling artinya penetapan sampel dilakukan apabila sifat atau unsur dalam populasi heterogen dan pengambilan jumlah sampel secara proposional.

Sampel dalam penelitian ini terdiri atas 100 petani dari total populasi yaitu 1.223 petani padi sawah di daerah irigasi Way Ketibung, dengan pembagian yaitu 82 petani dari Kecamatan Sidomulyo yang terdiri atas 22 petani dari desa Sidomulyo, 40 petani dari desa Sidowaluyo, dan 20 petani dari desa Sidorejo. Sedangkan untuk Kecamatan Candipuro tepatnya di Desa Sidoasri sebanyak 18 petani. 
Metode analisis data yang Wi digunakan untuk menjawab tujuan mengenai nilai kesediaan petani membayar jasa layanan pengelolaan irigasi dijawab dengan menggunakan metode pendekatan terbuka (open ended) CVM (Contingen Valuation Method) dengan berusaha menggali nilai kesediaan responden untuk membayar secara individu. Menurut Fauzi (2004), metode CVM merupakan metode yang digunakan untuk menilai secara ekonomi barang publik dengan cara menanyakan secara langsung kepada pengguna jasa layanan pengelolaan irigasi seberapa besar nilai maksimum yang bersedia dibayarkan sebagai komponen akibat kerusakan irigasi.

Metode CVM terdiri atas 4 macam desain kuesioner yang umum digunakan, yaitu metode pertanyaan langsung (direct question method/open ended), metode penawaran bertingkat (bidding game method), metode kartu pembayaran (payment card method), metode setuju atau tidak setuju (take it or leave method) (Prasmatiwi dkk, 2011). Munurut Setiyadi dkk (2016), nilai rataan WTP dapat dihitung dengan menggunakan rumus:

$\mathrm{EWTP}=\frac{\sum_{\mathrm{i}=1}^{\mathrm{n}} \mathrm{Wi}}{\mathrm{n}}$

Keterangan:

EWTP : Rata-rata nilai WTP (Rupiah/tahun)
: Besar WTP yang bersedia dibayarkan ke i

: Responden yang bersedia membayar

$\mathrm{n} \quad$ : Jumlah responden

Setelah dihitung nilai rataan WTP, selanjutnya dihitung nilai total WTP dengan menggunakan rumus:

TWTP $=$ EWTP $\times$ Ni

Keterangan:

EWTP : Total WTP (Rupiah/ tahun)

EWTP : Rata-rata nilai WTP

$\mathrm{Ni}$ : Jumlah populasi petani di Kecamatan Sidomulyo dan Candipuro

Tujuan mengenai faktor-faktor yang mempengaruhi petani dalam membayar jasa layanan pengelolaan irigasi di daerah irigasi Way Ketibung yaitu dengen menggunakan analisis ordinal logistik dengan persamaan sebagai berikut:

$$
\begin{aligned}
\mathrm{Z1}= & \operatorname{Ln}\left[\frac{P i}{1-P i}\right]=\alpha+\beta_{1} \mathrm{X}_{1}+\beta_{2} \mathrm{X}_{2}+\beta_{3} \mathrm{X}_{3}+ \\
& \beta_{4} \mathrm{X}_{4}+\beta_{5} \mathrm{X}_{5}+\beta_{6} \mathrm{X}_{6}+\beta_{7} \mathrm{X}_{7}+\beta_{8} \mathrm{X}_{8} \\
& +\mathrm{D} 1+\mathrm{e} \ldots \ldots \ldots \ldots \ldots \ldots \ldots \ldots \ldots \ldots \ldots \ldots \ldots \ldots \ldots \ldots \ldots \ldots \ldots \ldots \ldots \ldots \ldots \ldots \ldots \ldots \ldots \ldots \ldots
\end{aligned}
$$

Keterangan:

Z1 : Peluang $\mathrm{Z}(\mathrm{Y}=3)$ untuk petani yang bersedia membayar jasa layanan pengelolaan irigasi dengan jumlah rupiah tinggi. Peluang $\mathrm{Z}(\mathrm{Y}=2)$ untuk petani yang bersedia membayar jasa layanan pengelolaan irigasi dengan jumlah rupiah sedang. Peluang $\mathrm{Z}(\mathrm{Y}=1)$ untuk petani yang bersedia membayar jasa layanan pengelolaan irigasi dengan jumlah rupiah rendah

Pi : Peluang untuk menentukan tingkat kesediaan mmbayar 
jasa layanan pengelolaan irigasi bila Xi diketahui.

$\alpha \quad$ : Intersep

$\beta 1-\beta 8:$ Koefisien variabel bebas

$\mathrm{X} 1$ : luas lahan (ha)

X2 : pengalaman berusaha tani (tahun)

X3 : frekuensi terjadi kebanjiran (dalam 5 tahun)

X4 : frekuensi terjadi kekeringan (dalam 5 tahun)

X5 : pengetahuan petani terhadap fungsi irigasi (skor)

X6 : tingkat pendidikan (tahun)

X7 : pendapatan rumah tangga (kg/ha)

X8 : produktivitas $(\mathrm{kg} / \mathrm{ha})$

D1 : pekerjaan sampingan (1: ada, 0: tidak)

e : Error term

Model yang telah diperoleh perlu dilakukan uji signifikansinya dengan melakukan pengujian statistik yaitu uji serentak dan uji individual. Uji serentak dilakukan dengan LR statistik untuk memeriksa keberartian koefisien $\beta$ secara keseluruhan. Sedangkan uji individual untuk menentukan signifikansi parameter model dapat diuji dengan Wald Test yang digunakan untuk menunjukan apakah suatu variabel prediktor signifikan atau layak ada di dalam model.

\section{HASIL DAN PEMBAHASAN}

Responden dalam penelitian ini ratarata berusia 52 tahun dengan mayoritas tingkat pendidikan terakhir yaitu tamat SD sebanyak 46,00 persen. Rata-rata jumlah anggota keluarga responden yaitu 4 orang. Pengalaman usahatani padi sawah pada penelitian ini berkisar antara 5 hingga 45 tahun dengan rata-rata yaitu 27 tahun. Rata-rata produktivitas padi sawah musim tanam satu yaitu sebesar 5.668,5 $\mathrm{kg} / \mathrm{ha}$ dan musim tanam dua sebesar $5.464,5 \mathrm{~kg} /$ ha sehingga rata-rata produktivitas dalam satu tahun yaitu sebesar $11.133,1 \mathrm{~kg} /$ ha. Rata-rata pendapatan rumah tangga pada penelitian ini dihitung berdasarkan pendapatan on farm, non farm, dan off farm, yaitu sebesar Rp33.773.320/ tahun, sehingga rata-rata per bulannya yaitu Rp2.814.443/bulan, dimana sebagian besar pendapatan rumah tangga berasal dari usahatani padi sawah.

\section{Profil Usahatani Padi Sawah}

Rata-rata luas lahan yang diusahakan petani padi sawah dalam usahatani padi sawah yaitu sebesar 0,62 ha dengan status kepemilikan yaitu milik sendiri sebesar 0,61 ha dan sewa sebesar 0,01 ha. Persawahan di Kabupaten Lampung Selatan pada penelitian ini menggunakan sistem irigasi untuk pengairannya, yang berasal dari bendungan way ketibung. Usahatani padi sawah di Kabupaten Lampung Selatan tidak terlepas dari masalah kebanjiran dan kekeringan. Kebanjiran dan kekeringan 
yang terjadi merugikan petani padi sawah karena dapat menurunkan produksi padi sawah.

Frekuensi kebanjiran yang terjadi pada tahun 2015 hingga 2019 yaitu sebanyak 1 hingga 2 kali dimana kebanjiran terjadi pada tahun 2018, dan 2019. Kebanjiran terjadi dikarenakan irigasi yang tidak berjalan dengan baik karena terdapat bangunan pintu air yang runtuh di saluran primer dan sekunder sejak tahun 2018 dan sampai sekarang belum diperbaiki.

Frekuensi kekeringan yaitu sebanyak 1 sampai 3 kali yang terjadi pada tahun 2015, 2017 dan 2019. Kekeringan terjadi dikarenakan intensitas hujan yang jarang di musim gadu, selain itu juga karena menurut petani, bendungan way ketibung yang ada selama ini perlu diperluas karena bendungan tersebut dinilai relatif kecil untuk menampung air sehingga saat musim gadu tiba kebutuhan air untuk persawahan tidak tercukupi. Upaya mengatasi kekeringan yang terjadi yaitu dengan cara beberapa petani membuat sumur bor untuk mangairi persawahannya pada saat musim gadu.

\section{Analisis Kesediaan Petani Membayar Jasa Layanan Pengelolaan Irigasi di Daerah Irigasi Way Ketibung Kabupaten Lampung Selatan}

Sebanyak 100 persen petani di daerah penelitian bersedia membayar jasa layanan pengelolaan irigasi di daerah irigasi way ketibung. Adapun rata-rata kesediaan petani membayar jasa layanana pengelolaan irigasi dapat dilihat pada Tabel 1.

Tabel 1. Rata-rata kesediaan petani membayar jasa layanan pengelolaan irigasi per tahun

\begin{tabular}{clc}
\hline No & \multicolumn{1}{c}{ Keterangan } & $\begin{array}{c}\text { Rata-rata } \\
\text { pembayaran (Rp) }\end{array}$ \\
\hline 1 & Iuran perbaikan irigasi & 45.450 \\
2 & Biaya gotong royong & 16.750 \\
3 & Iuran buka tutup pintu air & 12.000 \\
4 & Pajak lingkungan & 13.080 \\
5 & Iiuran penanaman bunga & 10.120 \\
& sepanjang galengan & \\
\hline & Rata-rata WTP (tahun) & 97.400
\end{tabular}

Sumber: Data primer (diolah), 2020

Tabel 1 menunjukan nilai rata-rata dari 100 petani yang bersedia membayar jasa layanan pengelolaan irigasi yaitu sebesar Rp97.400/ha per tahun, artinya petani bersedia membayar sebesar Rp48.700/ha per musim tanam. Hal ini sejalan dengan penelitian Priambodo dkk (2014) yang menyatakan bahwa sebanyak 95,70 persen konsumen sayur-sayuran bersedia membayar untuk peningkatan kualitas sayuran menjadi organik, sedangkan sisanya sebesar 4,30 persen tidak bersedia untuk membayar dalam peningkatan kualitas tersebut dengan 
alasan bahwa konsumen telah merasa puas dengan kondisi sayuran yang dikonsumsi saat ini dan ketidak mampuan konsumen dalam membeli sayuran organik.

Total willingness to pay petani $\mathrm{di}$ daerah irigasi Way Ketibung yaitu sebesar Rp119.120.200 / tahun, atau sama dengan Rp59.560.100/MT. Hasil penelitian ini sejalan dengan penelitian Ladiyance dkk (2014), dimana kesediaan masyarakat dalam membayar jasa lingkungan udara di Badaracina, Jakarta Timur dalam upaya perbaikan lingkungan yaitu sebesar Rp23.226.923/tahun. Nilai tersebut lebih kecil dari nilai WTP petani di daerah irigasi Way Ketibung karena jumlah populasi di Badaracina lebih sedikit dibandingkan populasi petani pada penelitian ini, yaitu sebesar 450 responden. Besarnya nilai WTP yang berbeda-beda disebabkan karekteristik petani yang berbeda-beda juga.

Apabila pendapatan usahatani padi sawah cukup tinggi, dan luas lahan yang dimiliki cukup besar maka petani akan lebih bersedia untuk melakukan pembayaran jasa layanan pengelolaan irigasi. Hal ini sejalan dengan peneltian Dieny dkk (2018), yang menyatakan bahwa petani di daerah aliran sungai sekampung bersedia membayar jasa lingkungan air dengan kisaran antara
Rp10.000 hingga Rp250.000 dimana kesediaan membayar jasa lingkungan dipengaruhi oleh jumlah tanggungan, pendidikan, pendapatan dan lama bertani. Dengan sebaran kesediaan petani dalam membayar jasa layanan pengelolaan irigasi dapat dilihat pada Tabel 2.

Tabel 2. Sebaran nilai WTP petani (Rp/tahun)

\begin{tabular}{llrr}
\hline No & Nilai WTP (Rp) & $\begin{array}{r}\text { Jumlah } \\
\text { (Orang) }\end{array}$ & $\begin{array}{c}\text { Persentase } \\
(\%)\end{array}$ \\
\hline 1 & $45.000-115.000$ & 71 & 71 \\
2 & $115.001-185.001$ & 24 & 24 \\
3 & $185.002-255.000$ & 5 & 5 \\
\hline & Total & 100 & 100 \\
\hline
\end{tabular}

Sumber: Data primer (diolah), 2020

Tabel 2 menunjukkan bahwa petani bersedia membayar jasa layanan pengelolaan irigasi dengan kisaran antara Rp45.000 hingga Rp255.000. Dimana persentase terbesar berada pada range WTP Rp45.000 sampai Rp115.000. Hal ini dikarenakan sebagian besar petani beranggapan bahwa apabila pembayaran di atas Rp100.000, maka biaya untuk pemeliharaan dan perbaikan irigasi terlalu mahal karena pembiayaan untuk pemeliharaan irigasi saat ini sudah dibantu pemerintah. Petani memiliki beberapa pilihan metode pembayaran jasa layanan pengelolaan irigasi, seperti melalui kelompok tani, melalui prantara (Bank), melalui aparat desa (P3A), dan melalui lembaga pemerintah. Adapun sebaran petani berdasarkan metode pembayaran 
jasa layanan pengelolaan irigasi dapat dilihat pada Tabel 3.

\begin{tabular}{|c|c|c|}
\hline $\begin{array}{l}\text { pembayara } \\
\text { pengelolaar }\end{array}$ & $\begin{array}{l}\text { jasa } \\
\text { irig. }\end{array}$ & layanan \\
\hline Metode pembayaran & $\begin{array}{c}\text { Jumlah } \\
\text { petani (org) }\end{array}$ & $\begin{array}{l}\text { Persentase } \\
(\%)\end{array}$ \\
\hline $\begin{array}{l}\text { Melalui kelompok } \\
\text { tani }\end{array}$ & 17 & 17 \\
\hline $\begin{array}{l}\text { Melalui prantara } \\
\text { (bank) }\end{array}$ & 3 & 3 \\
\hline $\begin{array}{l}\text { Melalui aparat desa } \\
\text { (P3A) }\end{array}$ & 75 & 75 \\
\hline $\begin{array}{l}\text { Melalui lembaga } \\
\text { pemerintah (dinas }\end{array}$ & 5 & 5 \\
\hline Total & 100 & 100 \\
\hline
\end{tabular}

Sumber: Data primer (diolah). 2020

Tabel 3 menunjukan bahwa sebaran terbanyak berdasarkan metode pembayaran yang diinginkan petani yaitu melalui P3A sebesar 75 persen. Hal ini karena menurut petani apabila pembayaran dilakukan melalui P3A maka akan memudahkan kordinasi dalam proses pembayaran jasa layanan pengelolaan irigasi karena P3A merupakan organisasi yang bertugas mengawasi dan memperbaiki permasalahan irigasi. Sedangkan metode pembayaran melalui prantara bank merupakan metode yang paling sedikit dipilih petani yaitu sebesar 3 persen karena tidak semua petani mengerti proses transaksi melalui bank.

Tabel 4. Hasil analisis faktor-faktor yang mempengaruhi kesediaan petani dalam membayar jasa layanan pengelolaan irigasi

\begin{tabular}{|c|c|c|c|c|c|}
\hline Variable & $\mathrm{TH}$ & Coeff & z-Statistic & Prob. & Odd-ratio \\
\hline Luas lahan $(\mathrm{X} 1)^{* *}$ & + & $2,613861 * *$ & 2,858830 & 0,0043 & 13,6517 \\
\hline Pengalaman usahatani (X2) & + & 0,004598 & 0,149460 & 0,8812 & 1,0046 \\
\hline Frekuensi terjadi kebanjiran (X3) & + & 0,166838 & 0,328712 & 0,7424 & 1,1816 \\
\hline $\begin{array}{l}\text { Frekuensi terjadi kekeringan (X4) } \\
\text { Pengetahuan petani terhadap }\end{array}$ & - & $-0,122717$ & $-0,371665$ & 0,7101 & 0,8845 \\
\hline fungsi irigasi $(\mathrm{X} 5)^{*}$ & + & $0,155572 *$ & 1,775479 & 0,0758 & 1,1683 \\
\hline Tingkat pendidikan (X6) & - & $-0,029997$ & $-0,287891$ & 0,7734 & 0,9704 \\
\hline Pendapatan rumah tangga $(\mathrm{X} 7)^{* *}$ & + & $3,04 \mathrm{E}-08 * *$ & 1,989376 & 0,0467 & 1,0000 \\
\hline Produktivitas (X8) & + & $-0,000114$ & $-0,612265$ & 0,5404 & 0,9999 \\
\hline Pekerjaan sampingan (D1) & + & 0,098375 & 0,176419 & 0,8600 & 1,1034 \\
\hline Luas lahan $(\mathrm{X} 1)^{* *}$ & + & 2,613861 & 2,858830 & 0,0043 & 13,6517 \\
\hline \multicolumn{6}{|c|}{ Limit Points } \\
\hline LIMIT_2:C(10) & & 6,725100 & 3,693160 & 1,820961 & 0,0686 \\
\hline LIMIT_3:C(11) & & 9,820014 & 3,792517 & 2,589313 & 0,0096 \\
\hline Pseudo R-squared & & 0,222911 & LR statistic & & 32,78853 \\
\hline Prob(LR statistic) & & 0,000145 & & & \\
\hline $\begin{array}{l}* * \text { taraf signifika } \\
* \text { taraf signifikar } \\
\text { TH } \quad \text { Tanda }\end{array}$ & $\mathbf{a d}$ & $\begin{array}{l}\text { ersen } \\
\text { ersen }\end{array}$ & & & \\
\hline
\end{tabular}


Faktor-Faktor yang Mempengaruhi Kesediaan Petani Membayar Jasa Layanan Pengelolaan Irigasi di Daerah Irigasi Way Ketibung Kabupaten Lampung Selatan

Pembayaran jasa layanan pengelolaan irigasi merupakan kesediaan petani padi sawah dalam membayar perbaikan irigasi dalam upaya pengembalian fungsi irigasi sebagaimana mestinya. Faktor-faktor yang mempengaruhi kesediaan petani dalam membayar jasa layanan pengelolaan irigasi dianalisis dengan menggunakan analisis regresi logit. Hal ini sejalan dengan penelitian Fajria dkk (2020), dimana faktor-faktor yang mempengaruhi konsumen dalam kesediaan membayar terhadap sayuran organik di Pasar Modern Purwokerto dianalisis dengan menggunkan analisis logistik.

Variabel bebas yang digunakan dalam penelitian ini yaitu luas lahan (X1), pengalaman usaha tani (X2), frekuensi terjadi kebanjiran (X3), frekuensi terjadi kekeringan (X4), pengetahuan petani terhadap fungsi irigasi (X5), tingkat pendidikan (X6), pendapatan rumah tangga (X7), produktivitas (X8), dan pekerjaan sampinga (D1). Adapun faktorfaktor yang mempengaruhi kesediaan petani dalam membayar jasa layanan pengelolaan irigasi dapat dilihat pada Tabel 4.
Hasil analisis regresi logit ordinal yang tersaji pada Tabel 4 menunjukkan nilai Pseudo R-squared sebesar 0,222911, artinya sebesar 22,2911 persen dari variasi peluang petani dalam kesediaan membayar jasa layanan pengelolaan irigasi di daerah irigasi Way Ketibung Kabupaten Lampung Selatan dapat dijelaskan oleh variabel yang ada dalam model, sedangkan sisanya 77,7089 persen dijelaskan oleh variabel lain yang tidak dimasukan dalam model. Hal ini sejalan dengan penelitian Pringadi (2017), yang menyatakan bahwa nilai R Square untuk kesediaan petani membayar jasa lingkungan di daerah Sub DAS Air Sarap Kabupaten Aceh Selatan adalah sebesar 0,777. Artinya, sebesar 77,7\% kesediaan petani membayar jasa layanan pengelolaan irigasi mampu dijelaskan oleh variabel usia, pendapatan, jumlah tanggungan, pendidikan formal dan luas lahan. Sedangkan sisanya sebesar 22,3\% dijelaskan oleh variabel lain yang tidak dimasukkan ke dalam model.

Berdasarkan uji $\mathrm{z}$ terdapat satu variabel independen yang berpengaruh nyata terhadap peluang petani dalam kesediaan membayar jasa layanan pengelolaan irigasi di daerah irigasi Way Ketibung Kabupaten Lampung Selatan yaitu luas lahan (X1), pengetahuan petani 
terhadap fungsi irigasi (X5), dan pendapatan rumah tangga (X7), sedangkan pengalaman usahatani (X2), frekuensi terjadi kebanjiran (X3), frekuensi terjadi kekeringan (X4), tingkat pendidikan (X6), produktivitas (X8), dan pekerjaan sampingan (D1) tidak berpengaruh nyata terhadap peluang petani dalam kesediaan membayar jasa layanan pengelolaan irigasi di daerah irigasi Way Ketibung Kabupaten Lampung Selatan. Adapun variabel bebas yang nmempengaruhi petani dalam membayar jasa layangan pengelolaan irigasi yaitu luas lahan, pendapatan rumah tangga, dan pengetahuan petani terhadap fungsi irigasi.

Luas lahan berpengaruh nyata terhadap peluang kesediaan petani dalam membayar jasa layanan pengelolaan irigasi dengan nilai signifikansi atau nilai probability sebesar 0,0043 yang artinya luas lahan berpengaruh signifikan terhadap peluang petani untuk bersedia membayar jasa layanan pengelolaan irigasi. Luas lahan memiliki peluang odds rasio sebesar $13,6517 \quad$ yang mengindikasikan bahwa apabila terjadi kenaikan luas lahan sebesar satu hektar maka peluang petani untuk bersedia membayar jasa layanan pengelolaan irigasi akan meningkat sebesar 13,6517 kali jika diasumsikan variabel-variabel lain adalah tetap (ceteris paribus). Hal ini karena apabila ukuran luas lahan yang dimiliki petani luas maka kebutuhan air juga semakin bertambah sehingga petani akan bersedia membayar lebih apabila memiliki luas lahan sawah yang luas.

Pengetahuan petani terhadap fungsi irigasi berpengaruh nyata terhadap peluang kesediaan petani dalam membayar jasa layanan pengelolaan irigasi dengan nilai signifikansi atau nilai probability sebesar 0,0758 yang artinya pengetahuan petani terhadap fungsi irigasi berpengaruh signifikan terhadap peluang petani untuk bersedia membayar jasa layanan pengelolaan irigasi. pengetahuan petani terhadap fungsi irigasi memiliki peluang odds rasio sebesar 1,1683 yang mengindikasikan bahwa apabila semakin besar pengetahuan petani terhadap fungsi irigasi maka peluang petani untuk bersedia membayar jasa layanan pengelolaan irigasi akan meningkat sebesar 1,1683 kali jika diasumsikan variabel-variabel lain adalah tetap (ceteris paribus). Hal ini karena apabila petani semakin mengetahui fungsi irigasi dengan baik maka petani secara otamatis akan mengetahui manfaat yang akan didapatkan apabila pengelolaan dan pengawasan irigasi dilakukan dengan 
baik. Hal ini sejalan dengan penelitian Armia dkk (2020), yang menyatakan bahwa pengetahuan informasi petani memiliki hubungan yang nyata terhadap pengelolaan irigasi usahatani padi sawah di Kelurahan Margodadi Kecamatan Metro Selatan Kota Metro dengan signifikan sebesar 0,001 dan taraf kepercayaan 99 persen.

Pendapatan rumah tangga berpengaruh nyata terhadap peluang kesediaan petani dalam membayar jasa layanan pengelolaan irigasi dengan nilai signifikansi atau nilai probability sebesar 0,0467 yang artinya pendapatan rumah tangga terhadap fungsi irigasi berpengaruh signifikan terhadap peluang petani untuk bersedia membayar jasa layanan pengelolaan irigasi. Pengetahuan petani terhadap fungsi irigasi memiliki peluang odds rasio sebesar 1,0000 yang mengindikasikan bahwa apabila semakin besar pendapatan rumah tangga maka peluang petani untuk bersedia membayar jasa layanan pengelolaan irigasi akan meningkat sebesar 1,0000 kali jika diasumsikan variabel-variabel lain adalah tetap (ceteris paribus). Hal ini karena apabila petani memiliki pendapatan rumah tangga yang tinggi maka petani akan lebih mudah memenuhi kebutuhan pokok rumah tangganya, sehingga ketika kebutuhan pokok sudah terpenuhi maka petani akan lebih bersedia untuk berpartisipasi dalam membayar jasa layanan pengelolaan irigasi irigasi.

\section{KESIMPULAN DAN SARAN \\ KESIMPULAN}

Nilai dugaan rataan kesediaan petani membayar jasa layanan pengelolaan irigasi di daerah irigasi Way Ketibung Kabupaten Lampung Selatan yaitu sebesar Rp97.200 per tahun, atau sebesar Rp48.600 per musim tanam. Faktor-faktor yang mempengaruhi petani dalam kesediaan membayar jasa layanan pengelolaan irigasi di daerah irigasi Way Ketibung Kabupaten Lampung Selatan adalah luas lahan, pengetahuan petani terhadap fungsi irigasi, dan pendapatan rumah tangga.

\section{SARAN}

Sebaiknya pemerintah daerah membentuk suatu Badan Layanan Usaha milik pemerintah daerah Kabupaten Lampung Selatan yang berperan sebagai provider bagi petani dalam melaksanakan pembayaran jasa layanan pengelolaan irigasi sehingga dana WTP dapat dikelola dan digunakan untuk perbaikan irigasi. 


\section{DAFTAR PUSTAKA}

Armia, N. U., Gultom, D.T., \& Effendi, I. (2020). Persepsi Petani Anggota P3A Terhadap Pengelolaan Irigasi Usahatani Padi Sawah di Kelurahan Margodadi Kecamatan Metro Selatan Kota Metro. JIIA, 8 (2): 359-369.

Dasrizal., Ansofino., Juita., \& Jolianis. (2012). Model sistem pembayaran jasa lingkungan dalam kaitannya dengan konservasi sumber daya air dan lahan. Jurnal Program Studi Pendidikan Ekonomi STKIP PGRI Sumatera Barat, 1 (1) :19-20.

Dieny, F., Yuwon, S. B., Herwanti, S., \& Banuwa, I. S. (2018). Analisis Kesediaan Membayar Petani terhadap Jasa Lingkungan Air Irigasi DAS Sekampung. Jurnal Hutan Tropis, 6 (3): 227 -236.

Dinas Pekerjaan Umum Kabupaten Lampung Selatan. 2014. Peta Adiminiistratif Daerah Irigasi Way Ketibung. Lampung Selatan

Fajria, F., Ethika, D., \& Kusnaman, D. (2020). Analisis Kesediaan Membayar (Willingness To Pay) Konsumen Terhadap Sayuran Organik di Pasar Modern Purwokerto dan Faktor Yang Memengaruhi. SEPA, 17 (1): 40-48.

Fauzi, A. 2004. Ekonomi Sumber Daya Alam dan Lingkungan. PT. Gramedia Pustaka Utama. Jakarta.

Indah, L. S. M., Zakaria, W.A., \& Prasmatiwi, F.E. (2015). Analisis Efisiensi Produksi dan Pendapatan Usahatani Padi Sawah pada Lahan Irigasi Teknis dan Lahan Tadah Hujan di Kabupaten Lampung Selatan. JIIA, 3 (3): 228-234.
Ladiyance, S., \& Yuliana, L. (2014). Variabel-Variabel yang Memengaruhi Kesediaan Membayar (Willingness to Pay) Masyarakat Bidaracina Jatinegara Jakarta Timur. Jurnal Ilmiah WIDYA, 2 (2): 41-47.

Peraturan Daerah Kabupaten Lampung Selatan Nomor 15. 2012. Rencana Tata Ruang Wilayah Kabupaten Lampung Selatan Tahun 2011-2031. Lampung Selatan

Prasmatiwi, F. E., Irham., Suryatini, A., \& Jamhari. (2011). Kesediaan Membayar Petani Kopi untuk Perbaikan Lingkungan. Jurnal Ekonomi Pembangunan, 12 (2): 187-199.

Priambodo, L. H., \& Najib, M. (2014). Analisis Kesediaan Membayar (Willingness to Pay) Sayuran Organik danFaktor-Faktor yang Mempengaruhinya. Jurnal Manajemen dan Organisasi, 5 (1): $1-14$.

Pringadi. (2019). Faktor-faktor yang Mempengaruhi Kesediaan Petani dalam Membayar Jasa Lingkungan Air Padi Sawah. Jurnal AGRIFO. 4 (1): 52-57.

Setiyadi, H., Hartono, S., \& Darwanto, S.H. (2016). Consumer Willingness to Pay of Organic Rice and The Factors which Affected in Pontianak. Ilmu Pertanian (Agriculture Science), 1 (3): 130136.

Sudarma, I. M. (2014). Pembayaran Jasa Lingkungan Sebagai Instrumen Ekonomimenuju Pembangunan Berkelanjutan. Prosiding Seminar Nasional Prodi Biologi F. MIPA UNHI. pp. 18-26. 